\title{
A VARIEDADE ANGOLANA DO PORTUGUÊS: CONTEXTO HISTÓRICO E (SOCIO)LINGUÍSTICO
}

\author{
Kimavuidi Ferreira* \\ Paulo Osório**
}

RESUMO: A coabitação do Português com as línguas africanas em Angola propiciou a formação de uma variedade do português, que, em distintos momentos da história daquele país africano, se diferenciou e continua a diferenciar-se da variedade europeia, dando origem à variedade angolana, cuja consolidação começou sobretudo a partir da independência, em 1975, com a oficialização da língua europeia. Deste modo, o presente texto pretende traçar um panorama sociolinguístico e histórico que terá como foco a abordagem da situação da língua portuguesa em Angola, em duas fases distintas da sua história. Não deixaremos de observar, igualmente, a importância do kimbundu no enriquecimento do acervo linguístico da Variedade Angolana do Português (VAP).

PALAVRAS-CHAVE: Variedade angolana do português; Sociolinguística; Língua nacional; Interferências; Contacto.

\section{Introdução}

À semelhança de muitos países africanos, Angola é um país com um verdadeiro 'manancial linguístico' (COSTA, 2015, p. 10), o qual vive, por esta razão, uma verdadeira situação de plurilinguismo, uma vez que coabitam, no território em alusão, "três grandes

\footnotetext{
* Mestre em Estudos Lusófonos pela Universidade da Beira Interior (Covilhã, Portugal).

** Doutor, Pós-doutor e Agregado em Linguística Portuguesa. Professor Associado com Agregação na Universidade da Beira Interior (Covilhã, Portugal).
} 
famílias linguísticas, genética e estruturalmente muito diferentes umas das outras" (FERNANDES; NTONDO, 2002, p. 17), a saber: a família das LAs de origem Bantu, a família das LAs de origem não Bantu e, por último, a LP, de origem Neolatina. Fatores como "as relações estabelecidas por comunidades entre si, a emigração para países estrangeiros, a colonização e até mesmo o simples fato de se aprenderem línguas estrangeiras conduzem a uma inevitável coabitação linguística" (MOTA,1996, p. 505). No caso de Angola, a coabitação foi fruto da colonização, sendo que as duas primeiras famílias convivem no território que hoje constitui a República de Angola "há, pelo menos, 12.000 anos (FERNANDES; NTONDO, 2002, p. 23), ao passo que a língua portuguesa, tendo-se irradiado de Portugal, estabeleceu-se no século XV” (FERNANDES; NTONDO, 2002, p. 103), aquando da chegada à foz do rio Zaire, em 1482, do navegador português Diogo Cão, registando-se, assim, o primeiro contacto entre a LP com uma das línguas bantu faladas no território angolano, o kikongo, língua do grupo etnolinguístico bacongo. Concomitantemente, ao seu regresso a Portugal, volvidos dois anos, referem WhEELER e PÉLLISSIER, "Diogo Cão leva consigo quatro bacongos a quem desejava ensinar a LP, para que pudessem estabelecer-se relações entre os dois reinos, isto é, entre o reino de Portugal e o [então] maior reino bantu da África Central Ocidental", o reino do Congo (WHELLER; PÉLISSIER, 2011, p. 59), regiamente representados por D. João II e por Nzinga-a-Nkuwu ${ }^{1}$, respetivamente.

Contudo, para uma abordagem completa sobre o panorama linguístico angolano achamos pertinente fazê-lo tendo em conta os dois períodos a que Mingas faz referência: “o colonial e o pós-colonial” (MINGAS, 2000, p. 44-54). Sendo que em ambos os períodos a língua portuguesa gozou sempre de uma política diferente das demais línguas, isto é, das línguas locais, começaremos pela dissecação da situação linguística da primeira.

\footnotetext{
${ }^{1}$ O nome apresentado por Péllissier é 'Nzingo a Nkuwu'. Baseando-nos, todavia, em ZAU (2011, p. 94), optamos pela feminização do primeiro elemento do composto e pela hifenização.
} 
Quanto à abordagem das várias LAs faladas em Angola, dedicaremos particular atenção ao kimbundu, por se tratar de uma das línguas de Angola com mais tradição académica, mas também por, no universo das línguas de origem africana de Angola, parecer aquela que mais influência tem exercido quer no PE, quer na própria VAP, nos vários níveis de descrição linguística, fundamentalmente no enriquecimento lexical (ZAU, 2011).

\section{Situação linguística do português em Angola antes da independência}

O território que hoje constitui Angola assistiu à chegada portuguesa nos seus domínios no século XV (propriamente em 1482). Importa referir que na altura em que a caravana de Diogo Cão chega à terra que, mais tarde, viria a ser uma das mais vitais colónias de Portugal em África, aquele território era constituído por diferentes reinos, possuindo cada um a sua cultura e a sua língua. Mas

dada a implantação e consolidação do sistema colonizador, que se tornou proprietário e senhor daquelas terras, os reinos então existentes, e em tempos desavindos, foram unificados, à luz dos interesses coloniais, num território único, entre os séculos XV e XIX, emergindo, por conseguinte, a nação que hoje é Angola da qual a LP passou a ser o elemento de unidade nacional (ZAU, 2011 p. 95).

Entretanto, apesar da imposição da língua colonizadora, as línguas dos povos locais não deixaram de ser usadas, isto porque durante "a primeira colonização (séculos XV e XVI)" (GONÇALVES, 2012, p. 414)², não houve políticas linguísticas coloniais sólidas que objetivassem difundir a LP no seio da população colonizada, por um lado; e, por outro, talvez se deva ao fato de, como diz Calvet, poder tirar-se a um homem muitas coisas, mas nunca, nem mesmo em nome da língua de outros, tirar-lhe a sua própria língua com a sua anuência” (LOUIS-JEAN CALVET, 1974, p. 155, apud, MINGAS, 2000, p. 52). Em conformidade com Gonçalves, "a definição de uma política educacional [...] através da qual

${ }^{2}$ Material eletrónico, consultado a 13 de março de 2018 em https://books.google.pt/books?isbn=989732089X. 
pudesse ser desencadeada a difusão sistemática do Português, só ocorreu, portanto, na "segunda colonização (séculos XIX e XX)" (GONÇALVES, 2012), propriamente em 1930 (RAPOSO, op. cit., p. 159)". Sobre a mesma questão, Zau (2011, p. 95) assegura que

apesar de a língua portuguesa ser introduzida em Angola no século $\mathrm{XV}$, tinha fraca expressão até ao século XIX e mesmo durante toda a primeira metade do século XX. Com efeito, temendo a resistência das culturas e línguas africanas, e tentando, a todo o custo, impedir a crescente africanização da elite afro-portuguesa emergente nos séculos XVII a XIX (1620 a 1870), assiste-se, no século XVIII, à imposição de medidas legislativas a favor da língua e cultura portuguesas.

HAGEMEIJER (2016, p. 43), por sua vez, afirma, quanto ao assunto, que

até ao século XIX, o reconhecimento da África subsaariana limitouse na ocupação dispersa de zonas costeiras e ilhas, através de entrepostos, feitorias e fortalezas, dedicados a atividades económicas, tais como o tráfico de escravos e a produção de açúcar. O século XIX, e especificamente o período que se segue à Conferência de Berlim (1884-1885), marca o início da colonização efetiva de África.

Essa 'tardia colonização efetiva de África' refletiu-se, ou melhor, teve como consequência a também tardia difusão da LP nas antigas colónias lusitanas, de tal sorte que “em 1975, apenas 1 a 2\% da população angolana (só para citar o contexto em análise) falava o Português como língua materna e 15 a 20\% tinha-o como L2 ${ }^{3}$, isto é, como língua não materna" (HAGEMEIJER, 2016, p. 46). A concretização de uma política linguística definida verificou-se apenas em 1930. Para o sucesso da mesma "foi então adotado o modelo ‘assimilacionista' francês, segundo o qual a língua colonial, isto é, o Português deveria ser a

\footnotetext{
${ }^{3}$ A L2 (também conhecida como LS ou ainda SL - língua segunda ou segunda língua) está para outra que não a primeira, isto é, a língua materna. Sendo assim, os termos L2, LS, SL são usados para classificar toda a aprendizagem e uso de uma língua não materna, gozando essa aprendizagem e/ou uso de um estatuto linguístico, ao contrário do que acontece com a aprendizagem de uma LE (língua estrangeira).
} 
única língua de contato no ensino e o instrumento que devia propiciar a assimilação cultural" (BARRETO, 1977, apud RAPOSO, op. cit., p. 159). Desta forma, o Português tornouse a única língua autorizada nas escolas, ficando o uso das línguas locais reservado para a instrução religiosa. Como se pode constatar, no período colonial, "a política portuguesa de ensino teve como objetivo a imposição da Língua Portuguesa em detrimento das línguas locais”. Consequentemente, MINGAS (2000, p. 48) refere que

a aplicação prática desta política linguística foi apoiada por uma vigilância cada vez mais acentuada da polícia política PIDE, que considerava como atitudes subversivas a utilização de qualquer uma das línguas locais ou mesmo o uso de vestuários locais pelos assimilados. Essa política era seguida à risca pelos portugueses, de tal sorte que o ensino era ministrado somente em Português, neutralizando, assim, as línguas locais, para a concretização dos seus desígnios, à exceção das escolas dirigidas por missionários, onde as línguas nativas podiam ser usadas como meio de auxílio à aprendizagem do Português, ao passo que nas escolas primárias a única língua ensinada era o Português.

A mais inequívoca prova das intenções glotofágicas da política linguística portuguesa nas suas colónias consta do Decreto no 77 de 9 de dezembro de 1921 (CHICUNA, 2014, p. 41), no qual Norton de Matos ${ }^{4}$ determina o seguinte:

Art. $2^{\circ}$ - Não é permitido ensinar, nas escolas das missões, línguas indígenas;

Art. $3^{\circ} \mathrm{O}$ uso das línguas indígenas só é permitido, em linguagem falada, na catequese, e como auxiliar, no período do ensino elementar da Língua Portuguesa;

$\int 1^{\circ}$ É vedado, na catequese das missões, nas suas escolas, e em qualquer relação com os indígenas, o emprego das línguas indígenas por escrito ou de outra língua que não seja a Portuguesa, por meio de folhetos, jornais, folhas avulsas e quaisquer manuscritos.

\footnotetext{
${ }^{4}$ Governador-Geral de Angola entre 1913 e 1914 e Alto-Comissário da República de Angola de 1921 a 1923 (CHICUNA, 2015). Cf., igualmente, MATOS (2004, p. 236) Memórias e Trabalhos da Minha Vida, livro digital, consultado em 2 de março de 2018 em https://books. Google.pt/books?isbn=9728704305.
} 
Uma das consequências dessa política, assevera MINGAS (2000, p. 50), foi que “a partir dos anos de 1925/1930, os filhos dos (nativos) 'assimilados' começaram a ter o Português como língua primeira". Contudo, a condição bilingue (kimbundu/português) dos pais foi o vetor de muitas interferências. Estas, todavia, não proviam simplesmente dos assimilados, porque mesmo os portugueses que moravam na periferia eram eles também bilingues português/kimbundu. Assim sendo, e atendendo à especificidade da colonização de Angola, caraterizada pelo povoamento, à medida que se progredia do centro da cidade em direção à periferia, o número de locutores monolingues portugueses diminuía, aumentando o número de locutores bilingues (kimbundu/português) e monolingueskKimbundu. Mesmo não tendo espaço de utilização nas escolas ou nas atividades públicas, o kimbundu e outras línguas locais resistiram às políticas linguísticas coloniais, nocivas à sua existência. Fatores como o difícil acesso à escola por parte dos nativos, o processo de colonização tardia de Angola, a chamada colonização maciça e o estabelecimento, igualmente, tardio de políticas linguísticas que visassem a difusão massiva e sistemática do português contribuíram, portanto, para a resistência das línguas locais; pois embora a LP fosse a única autorizada para o ensino, a criação de escolas que assegurassem a sua difusão foi levada a cabo apenas em meados dos anos 40, sendo que só na década de 60-70 se registou um crescimento considerável de escolas nos vários níveis de ensino (RAPOSO, ibidem).

\section{Situação atual da língua portuguesa em Angola}

Alcançada a independência, a 11 de novembro de 1975, obviamente que se impôs à jovem Nação um dos problemas mais cruciais das muitas nações africanas recentemente criadas: o das suas línguas nativas, que por terem sido e continuarem a ser tão pouco cultivadas, por um lado, e pela sua diversidade, por outro, nenhuma delas é usada como meio comum de comunicação para propósitos modernos (HAUGEN, 1974, p. 107). A nosso ver, entretanto, a diversidade linguística não constitui barreira para a união na diversidade, 
pois há contextos linguísticos tão diversificados (como é o caso da Índia, com catorze línguas oficiais, portanto, um exemplo típico) onde, nem por isso, a diversidade leva à subvalorização das línguas locais. Mas pela razão acima apontada por Haugen, a verdade é que mesmo que a sua adoção como língua oficial tenha sido 'forçada' (ou talvez não), a língua portuguesa não perdeu o estatuto atribuído enquanto o país esteve sob o domínio colonial. Antes pelo contrário, no período pós-colonial, teve início um importante processo de difusão e valorização da LP em Angola, porquanto a mesma continuou a ser vista (tal como já os assimilados a viam) como a língua de prestígio e de ascensão social. Este processo de difusão e de valorização do português permitiu aumentar o seu número de falantes. A pluralidade etnolinguística de Angola favoreceu a conferência de um estatuto diferenciado à LP, por causa da sua “operacionalidade” (GANHÃO, 1979, apudRAPOSO, op. cit., p. 157). Tida como elemento unificador entre os vários grupos etnolinguísticos que compõem o 'mosaico cultural angolano’ e como a língua “que garante a unidade nacional e permite, de forma mais eficaz do que as outras línguas locais, as relações internacionais e a transmissão do conhecimento científico", a LP foi adotada como Língua Oficial pelo Governo angolano, após a independência, conforme consta da Constituição (2010) ${ }^{5}$ da República de Angola, no ponto $\mathrm{n}^{\circ} 1$ do Artigo $19^{\circ}$.

Segundo Raposo (ibidem), a "Língua Oficial (LO) é a usada pelo governo e instituições públicas na comunicação a nível nacional e internacional. Em contextos multilingues, como é o caso dos países africanos em geral, a 'Língua Oficial' nem sempre é a língua materna da maior parte dos cidadãos". Ademais, "para além do seu estatuto de língua oficial, a LP, em Angola, é hoje a língua materna de muitos angolanos, e com o seu alastramento constitui a língua nacional $(\mathrm{LN})$ no sentido pleno e veicular para todos os angolanos, embora o grau de domínio não seja igual para todos" (FERNANDES; NTONDO, 2002, p. 19). É indubitável que, em Angola, “a LP exerce um papel plurifuncional, de usos nos domínios da vida sócio-política-económica e cultural, e veicular no país, pois funciona

${ }^{5}$ Disponível em https://www.icjp. pt/sites/default/files/media/583-502.pdf. Consultado a 2 de agosto de 2017. 
como elo entre os vários grupos etnolinguísticos" (NTONDO; FERNANDES, 2002), como já anteriormente foi referido.

Mas a consideração da LP por como 'língua nacional' em Angola suscita interrogações, visto que essa posição vai ao encontro daquilo que latamente os estudos atestam, porquanto é frequente a LP ser descrita como LN apenas em Portugal e no Brasil, sendo, portanto, considerada como LO nos PALOP. Considerando, porém, o conceito de LN apresentado por Mwatha Ngalasso (apud MINGAS, 2000, p. 55), por um lado, e por DUCROT e TODOROV (1982, p. 81), por outro, pode aduzir-se que a situação da LP em Angola apresenta condições para ser considerada como tal (como língua nacional).

Sendo o Português a LO de Angola, a mesma passa a ser considerada também língua nacional. Apesar da pluralidade que carateriza o contexto linguístico angolano, não há margem para dúvida de que, em Angola, nenhuma outra língua, senão a portuguesa, desempenha o papel de língua de administração e de Estado. De igual modo, é indubitável que a mesma é falada a nível do território nacional, que já reflete a herança cultural de grande parte da população angolana e que é o suporte da sua expressão literária, uma vez que grande parte do acervo literário angolano é, quase ele todo, concebido em português. Citando Ngalasso (op. cit., p. 56),

... a língua nacional designa toda a língua de origem autóctone qualquer que seja a sua importância geográfica ou demográfica, quer seja maioritária ou não, e língua oficial, toda a língua nacional ou não, à qual é conferido o privilégio de servir de meio de comunicação nas instituições do Estado.

O que se pode depreender do conceito acima é que uma língua nacional pode ser ela também oficial. Contudo, a língua oficial não precisa necessariamente de ser nativa para ser considerada nacional, desde que se verifiquem, portanto, os requisitos englobados nos conceitos: seja falada no interior de um Estado e sirva de comunicação nas suas instituições, 
faça parte do seu património cultural (ZAU, 2011, p. 59), represente um elemento caraterizador da consciência nacional e seja o suporte da sua expressão literária. Zau (2011, p. 116) admite que

a discussão em torno da nacionalização da LP em Angola tem vindo a acentuar-se cada vez mais, e que o interesse pela temática não é apenas uma consequência da sua dinâmica expansão territorial, como também, e principalmente por estar a tornar-se uma das línguas maternas com maior número de falantes, não obstante a associação que dela se faz ao colonialismo.

Segundo o autor, “apesar de, em Angola, a expressão 'língua nacional' ser usada como o principal elemento distintivo entre as LAs e a LP, é com naturalidade que tanto esta como aquelas se enquadram no perfil anunciado nos conceitos de língua nacional. Sendo assim, independentemente das discussões que esta matéria possa implicar, como, por exemplo, a necessidade (i) de um levantamento do português fundamental, isto é, mais usual, e o que ele traduz em termos de uso pela população angolana, por áreas geográficas, a nível da compreensão, expressão oral e expressão escrita; (ii) de um estudo apurado sobre a descrição fonética, morfossintática e semântica, passível de delimitar as marcas desse português (ZAU, 2011, p. 117), a LP parece já exercer a função de língua nacional, cabendo aos decisores a criação de condições (materiais e humanas) que a envolvência do assunto exige. Atendendo à heterogeneidade linguística de Angola, a adoção da LP como LO, por um lado, e a nacionalização da mesma, por outro, revela-se suficientemente flexível e adaptável para servir as realidades angolanas, principalmente na resolução do problema da unidade nacional e no exercício de determinadas funções que as línguas locais teriam dificuldades em exercer (ZAU, 2011, p. 116-118)". Quanto ainda às funções que a LP desempenha em Angola, Silva (2015, p. 37-38) refere que

a partir do princípio ativo da mesma, é possível, em sociedades multilingues, proceder a uma repartição de funções, de acordo com vários aspetos de natureza histórica, política, ou social. Nesta perspetiva, Angola é um exemplo paradigmático pois, a existência de várias 
línguas desencadeia tal atribuição. Deste modo, a Língua Portuguesa desempenha, em Angola, várias funções diferentes das línguas autóctones.

A LP, hoje, em Angola, é, sem dúvida, o principal instrumento de unidade nacional, de Cabinda ao Cunene, e constitui, pese embora a discordância e/ou o ceticismo em torno desta questão, uma língua nacional de Angola, tal como as demais. Em Angola coabitam várias 'línguas nacionais', sendo uma delas o Português, de origem europeia, e as outras, a maioria, de origem bantu. Contudo, se, por um lado, a sua adoção como LO e, consequentemente, de escolaridade e veicular dirime possíveis conflitos entre os vários grupos etnolinguísticos que enformam o 'mosaico social' angolano, por outro, a mesma continua (tal como o era no período colonial) a ser um dos principais fatores de exclusão social, uma vez que a sua sobrevalorização parece não levar em conta a projeção social das populações que não a dominam, cujo número, segundo COSTA (2015, p. 44-45), "na realidade, ainda é bastante grande, sobretudo nas zonas rurais", embora "dados divulgados pelo INE, obtidos no Censo de 2014, revelem que, num universo de aproximadamente 25,7 milhões de angolanos 71,15\% falam português” (HAGEMEIJER, 2016, p. 46). Assim, Costa considera que

o fato de o Português ser a única língua de trabalho na administração e no sistema educativo não deveria levar à marginalização das línguas nacionais, por se constituírem, a par do Português, um património histórico-cultural de extrema importância para os angolanos (COSTA, 2015, p. 22).

A subvalorização das línguas africanas faladas em Angola tem as suas raízes nas políticas linguísticas coloniais, é bem verdade; mas também não deixa de ser um ‘facto’ que neste quase meio século de independência que Angola tem (embora reconheçamos também

\footnotetext{
${ }^{6}$ Não pretendendo pôr em causa os dados divulgados pelo Instituto Nacional de Estatísticas, é, contudo, irrefutável o ponto de vista de Costa, se se tiver em conta que o grau de acesso e exposição ao Português tem maior expressão nos centros urbanos.
} 
que a guerra civil tenha atrasado o desenvolvimento do país em muitos aspetos), pouco se fez para mudar o quadro, já que continua a haver pouco empenho para a materialização do que está legislado acerca das línguas autóctones, conforme veremos nos parágrafos sucedâneos. Muito pelo contrário, a democratização da LP a seguir à independência (e mesmo antes desta) teve um impacto direto nas relações diglóssicas instáveis em Angola, uma vez que tal resultou, desde os primórdios desse convívio, no "afastamento das línguas locais no contexto político-administrativo, resultando na contínua e exclusiva protagonização da LP, no desempenho das funções linguísticas mais importantes” (COSTA, 2015, p. 64).

\section{As línguas africanas no contexto linguístico angolano}

Sendo a língua o veículo da transmissão cultural geracionalmente, a ausência de políticas linguísticas que visem a mantê-las vivas leva, decerto, ao desaparecimento das mesmas. Cremos ter sido com base na tomada de consciência deste perigo que, logo após a independência, o Governo angolano criou condições objetivas para que as línguas locais tivessem o mesmo estatuto que a Língua Portuguesa, tendo sido uma dessas políticas a criação, em 1979, de uma organização especializada, o Instituto Nacional de Línguas (que, em 1983, tomou a designação de ILN - Instituo de Línguas Nacionais), com o objetivo de proceder a investigações sobre a situação linguística do país, no que tange às línguas locais (MINGAS, 2000, p. 54). Mas a existência, por si só, de um organismo cuja conceção teve como fundamento o fato acima exposto não soluciona o problema sobre a subvalorização das línguas nativas, a menos que as políticas gizadas em torno destas sejam, de fato, materializadas. A não materialização dessas políticas está na base do descaso das LAs em Angola.

Dada à sua diversidade quer em Angola quer em toda a África, as LAs integram grupos distintos, divididos por famílias, segundo Greenberg (1963), apud Chicuna (2015, p. 26). Assim, Greenberg compartimenta as línguas africanas em quatro grandes famílias linguísticas, indicando, ao mesmo tempo, a respetiva subfamília, tal como se segue: Família Afro-Asiática (subfamílias: integra as línguas Berberes do Norte de África, as Cushítica da Etiópia e da Somália e ainda as Semitas, incluindo o hebreu, o árabe e o aramaico); Família 
Nilo-Sahariana (subfamílias: Sudanês, Sahariano, Songhai, Fur, Chari-Nilo, koman); Família Congo-Cordofaniana (Subfamílias: Níger-Congo e Cordofaniana). Na subfamília Níger-Congo, inclui numerosos grupos predominantes para sul do Sahara, de que destacamos os Bantu, a sul do equador); Família Khoisan (Subfamílias: Khoi, San, Sandawe, Iraqw, Hatsa ou Hazda). Desta família fazem ainda parte as línguas dos Pigmeus da floresta do Congo Democrático e línguas faladas "com cliques ${ }^{7 “ ~[. . .], ~ v u l g a r m e n t e ~ c o n h e c i d o s, ~ e m ~}$ Angola, como Hotentotes, Bosquímanos ou ainda Mukankala".

\section{Línguas bantu}

Segundo Fernandes e Ntondo (2002, p. 67), o termo “"bantu” foi proposto pelo alemão BLEEK, em 1960”. Quanto a este dado, Chicuna (2015, p. 27) refere, todavia, que o termo foi utilizado pela primeira vez pelo mesmo autor, mas em "1962, para se referir ao conjunto de línguas faladas maioritariamente na África subequatorial, desde os montes Camarões até à África do Sul, apresentando caraterísticas comuns, e que designavam o(s) ser(es) humano(s) por muntu (singular)/bantu (plural)".

Quer Fernandes e Ntondo (2002) quer Chicuna apontam para o fato de as investigações de Bleek acerca das línguas bantu (LB) não terem sido as primeiras, pois que o reconhecimento da unidade dessas línguas, segundo Kukanda (1986, p. 6), já tinha sido confirmado pelo português B. Rebelo de Aragão, dois séculos antes do investigador alemão.

O alcance da independência permitiu ao Governo angolano a criação de condições que objetivavam conferir às línguas nacionais os mesmos estatutos conferidos à LP. Assim, tendo em conta as investigações levadas a cabo pelo INL chegou-se à conclusão de

\footnotetext{
7 "Do inglês click, significa estalo. O clique constitui uma consoante para as línguas que o possuem. Linguisticamente, é um som com duas oclusões: uma oclusão principal, quer pelos lábios quer pela parte anterior da língua contra os dentes ou contra o palato, e que produz diferentes tipos de cliques (labial, dental, palatal e lateral); uma segunda oclusão, dita de apoio, obrigatoriamente velar, produzida pela elevação da parte posterior do dorso da língua contra o palato mole." (FERNANDES; NTONDO, 2002, p. 65).
} 
que em Angola são faladas LB, as quais pertencem à família Congo-Cordofaniana, e línguas não bantu $(\mathrm{LnB})$, pertencentes à família Khoisan, de acordo com a supracitada classificação de Greenberg. Segundo a comparative bantu, "as línguas bantu faladas em Angola pertencem a três ZONAS linguísticas, representadas pelas letras H, K e R" (FERNANDES; NTONDO, 2002, p. 68). MALCOM GUTHRIE (1967), apud Fernandes e Ntondo (2002, p. 93), afirma que "a ZONA H reúne as línguas Kikongo e Kimbundu; a ZONA K engloba as línguas Cokwe e Ngangela, ao passo que da ZONA R fazem parte as línguas Umbundu, Oshikwanyama, Oshindonga, Oshihelelo e Olunyaneka”.

Pela sua abrangência a nível do território angolano, Redinha (1975, p. 8), destaca, dentre as línguas faladas em Angola, nove (9) principais:

O Kikongo, língua que cobre boa parte da região Nordeste (sic) de Angola, nomeadamente as províncias de Kabinda, Wije, Zaire e a parte norte da província do Bengo. A área de difusão do Kikongo estende-se para além das fronteiras de Angola, sendo também falado na RDC, na República do Gabão e no sul da República do Congo Brazzaville; o Cokwe, cuja área de difusão abrange a totalidade das províncias da Lunda Norte e Sul, a província do Muxiku ${ }^{8}$, estendendo-se, profundamente, para a província do Kwandu Kubangu. O Cokwe é, entretanto, uma língua transnacional, à semelhança do Kikongo. ${ }^{9}$; o Kimbundu, que parte do interior para o litoral, compreendendo as províncias do Bengo, Kwanza Norte, Malanje, Lwanda e o norte da província do Kwanza Sul; o Ngangela, falado na província do Kwandu Kubangu, no sudoeste das províncias do Muxiku e do Viye, bem como na parte leste da província da Wíla. É também uma língua transnacional, por algumas das suas variantes terem ramificações e serem faladas na República da Zâmbia; o Umbundu, cuja área de difusão engloba as províncias do Viye, Wambu e de Bengela. Todavia, a sua influência é também notável nas províncias do Namibe, do Kwandu Kubango (a noroeste) e a norte da província da Wíla; o Olunyaneka, que tem como centro de difusão as províncias da Wíla e do Kunene, e com alguma influência nas províncias de Bengela e Namibe; o Oshihelelo, por sua vez, tem

\footnotetext{
${ }^{8}$ Grafia proposta por Fernandes e Ntondo (2002).

9 A sua área de difusão estende-se para além do território angolano, em países como a RDC (República Democrática do Congo) e a República da Zâmbia.
} 
como zona de difusão a província do Namibe; a língua Oshikwanyama, falada na província mais a sul de Angola, o Cunene, tem, porém, influência notável no norte da Namíbia, onde é tida como uma das línguas maioritárias. Ao contrário do que se verifica em Angola, na Namíbia, o Oshikwanyama exerce também um papel plurifuncioanl, sendo ensinada até à terceira $\left(3^{a}\right)$ classe; e, por último, o Oshindonga, que se circunscreve numa área muito restrita, isto é, no sudoeste da província do Kwandu Kubango. Conta, igualmente, com um número razoável de locutores na Namíbia.

Retomando Chicuna, atualmente, em consequência de diversas investigações, o termo bantu está associado a duas realidades: à língua e à cultura, por um lado, e à população, por outro, pelo que as línguas bantu designam todas as línguas faladas do sul dos Camarões até à África do Sul. Segundo, dada a associação que se estabelece entre as línguas e a respetiva população falante, o povo bantu abarca o conjunto de populações da África subequatorial que falam línguas da mesma família, embora pertençam a tipos étnicos muito diversos, ou seja, em África, a designação de uma língua corresponde à designação do respetivo grupo etnolinguístico ou à respetiva etnia; pelo que "classificar as LB significa classificar as diferentes etnias bantu” (OBENGA, 198, p. 21).

Sendo assim, a língua Kokwe corresponde ao grupo etnolinguístico Tukokwe; a língua Kimbundu corresponde ao grupo etnolinguístico Ambundu; a língua Kikongo corresponde ao grupo etnolinguístico Bakongo; o Ngangela corresponde ao grupo etnolinguístico Vangangela; a língua Olunyaneka corresponde ao grupo etnolinguístico Ovanyaneka-Nkumbi; a língua Oshihelelo corresponde ao grupo etnolinguístico Ovahelelo; a língua Oshikwanyama corresponde ao grupo etnolinguístico Ovakwanyama, sendo este, por sua vez, à semelhança do grupo Ovandonga, subgrupo do grupo Ovambo. A língua Oshindonga corresponde ao grupo etnolinguístico Ovandonga e, por último, a língua Umbundu corresponde ao grupo etnolinguístico Ovimbundu, o maior de Angola, com 
mais de 1.500 .000 pessoas, segundo Fernandes e Ntondo (2002, p. 55). O mapa ${ }^{10}$ abaixo ilustra, resumidamente, o que acabamos de expor:

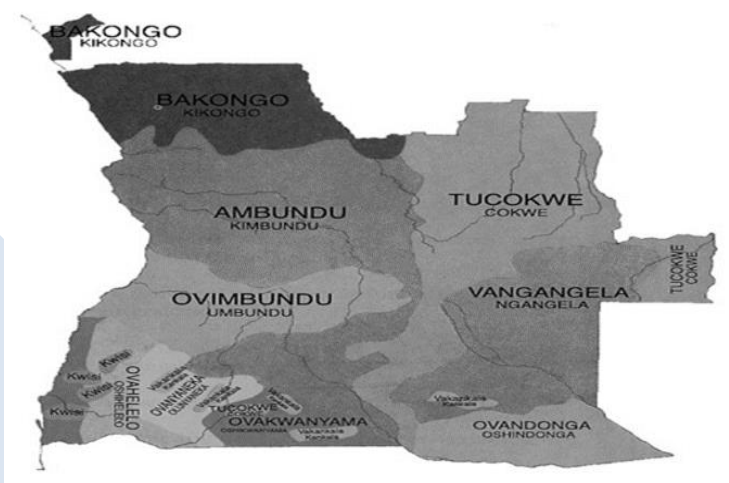

\section{Caraterísticas gerais das línguas bantu}

Em relação às caraterísticas das línguas bantu, embora sejam notáveis diferenças mínimas entre as LB, estas apresentam uma unidade genealógica" (FERNANDES; NTONDO, 2002, p. 67). Em termos gerais, as LB assemelham-se em termos fonéticas, morfológicas, semânticas e lexicais (CHICUNA, 2015). As caraterísticas que, muito resumidamente, apresentaremos são as consideradas de maior relevância, tendo como base Fernandes e Ntondo (2002, p. 68-69).

A primeira grande particularidade que distingue as LB, se comparadas com outras como, por exemplo, o Português, é a não existência da marca do singular e do plural, pois que os nomes são caraterizados por morfemas flexionais prefixais, que indicam a oposição

${ }^{10}$ Instituto de Geodesia e Cartografia de Angola, Mapa Etnolinguistico de Angola (adaptado), apud Fernandes e Ntondo (2002, p. 57). Consultado a 15 de março de 2018 em https://triplov.com/letras/americo-correia-oliveira/literatura-angolana/anexo3.htm. 
singular/plural; pelo que a classificação dos substantivos é feita em função desses morfemas prefixais, indicadores da oposição entre as categorias numéricas. Quer dizer, as LB apresentam um sistema de classes ${ }^{11}$, caraterizado por vários prefixos nominais, que indicam o singular e o plural. Chatelain aponta para a existência de 10 classes substantivais. Fernandes e Ntondo, no entanto, apontam para a existência de dezoito (18), com base em estudos atuais (op. cit., p. 68).

Tomemos como exemplo o substantivo kináma ('perna', em Kimbundu), pertencente à classe III. Em Kimbundu, para pluralizar este nome, não se aplica o molde de pluralização do Português, segundo o qual o morfema flexional numérico $-s$ é posposto ao lexema, flexionando-se assim em kinámas. De acordo com o padrão de pluralização das línguas bantu em geral, e do Kimbunbu, em particular, os nomes da classe III formam o plural antepondo o morfema prefixal $i$-à palavra que se deseja pluralizar. Por conseguinte, aplicando-se este molde de flexão numérica, o plural de kináma, propriamente dito, é ináma (e não kinámas, tal como é pluralizado na VAP, por influência, deduzimos, do molde de pluralização do $\mathrm{PE})$.

Outra caraterística das línguas bantu é a inexistência de artigos e de género com conotação sexual. Por exemplo, o nome mubika (termo da língua Kimbundu) é usado tanto para o masculino quanto para o feminino, significando, escravo(a). Corresponde, portanto, aos chamados substantivos comuns de dois géneros, em LP, considerados por Chatelain (1888-89, p. 40) ${ }^{12}$ como epicenos.

O sistema vocálico das línguas bantu é simétrico, quer dizer que o mesmo comporta uma vogal central $(a)$ e um número idêntico de vogais anteriores $(i, e)$ e de vogais posteriores $(u, o)$. Algumas consoantes orais como as oclusivas [b], [d], [g], só para citar

\footnotetext{
11 "A classe constitui um sistema que permite aos substantivos participar de forma evidente na expressão da distinção singular/plural. Assim, a passagem de uma classe à outra faz-se através da substituição dos morfemas prefixais [...] ou da adição destes [...].” Cf. Fernandes; Ntondo, 2002, p. 77-78.

12 Material digital, consultado a 20 de setembro de 2017, em https://archive.org/details/kimbundugrammar 00chatgoog.
} 
algumas, não aparecem de forma isolada, por serem sempre pré-nasalizadas, formando grupos indivisíveis. Assim: [mb] em mbuta; [nd] em ndoki, [ñg] em ngwvulw, por exemplo.

A maioria das LB utiliza tons, variação de altura ${ }^{13}$ no interior de um mesmo lexema que permite opor duas unidades lexicais de sentido diferente, mas cujo contexto fonético é idêntico, permitindo identificar a existência de vogais breves e longas, tal com sucede em zinga (viver), na qual a vogal i é breve e quïnga (embrulhar), em cuja duplicação da mesma vogal representa o tom longo. Em termos diacríticos, a representação gráfica da vogal longa é marcada pelo acento circunflexo (zînga);

Em termos ortográficos, as línguas bantu não diferem muito da LP, pelo fato de naquelas ser também utilizado o alfabeto latino. As vogais da LP, mormente as orais, são idênticas, apesar de o sistema vocálico das Línguas Bantu (especificamente o das línguas faladas em Angola) ser muito simplificado, por não conter vogais nasais, com exceção do Umbundu. A natureza fonética das LB concorre, todavia, para a existência de algumas diferenças, não obstante as semelhanças apontadas. A maior divergência assenta, sobretudo, na escrita. Relativamente a isto, basta citar as contradições atualmente existentes na grafia de alguns topónimos angolanos, muitos dos quais já anteriormente apresentados, como é o caso de Wíla, Lwanda, Muxiku, atualmente grafados Huila, Luanda, Moxico. Há de se convir que tal falta de uniformização ortográfica é motivada ou pela falta de uma política linguística efetiva ou pela falta de coerência na materialização das políticas existentes, como já atrás apontamos, uma vez que a Lei de Bases da Toponímia14 (2016) é clara quanto aos critérios ou às normas que devem ser observadas, as quais devem ser certificadas pelo ILN.

\footnotetext{
${ }^{13}$ Em termos linguísticos, "a altura de um som explica-se pela frequência das vibrações do fundamental desse som. Fisiologicamente, tem a sua causa nas dimensões e na tensão das cordas vocais, o que explica que a altura de um som varie com o sexo, a idade, a altura do indivíduo, etc., e varie no decorrer do discurso" (DUCROT; TODOROV, 1982,

${ }^{14}$ Para uma ideia mais abrangente sobre o assunto, leia-se, por exemplo, o Art. $7^{\circ}$ (pontos 1 e 2) da referida Lei, disponível em studiosvdv.com/ADRA/I-155-Diario-da-Republica.pdf (consultado a 9 de maio de 2018).
} 


\section{Línguas não bantu - caraterísticas gerais}

Tal como nos referimos anteriormente, as investigações empreendidas pelo Instituto Nacional de Línguas conduziram à constatação de que, além das LB, em Angola são também faladas LnB, entre as quais se destacam as línguas Khoisan e a língua Vátwa. Estas línguas são consideradas não bantu porque os grupos etnolinguísticos que as falam não pertencem ao grupo bantu, em conformidade com Wheeler e Péllissier (2016, p. 36):

existem três pequenos grupos não bantu em Angola, os povos khoisan, que tiveram origem nos grupos bosquímano e hotentote: os bosquímanos, os cuissi e os cuepe. Contando apenas cerca de dois mil a seis mil indivíduos, são sobretudo nómadas do deserto. Últimos representantes de antigos caçadores-recolectores da velha Angola, estes homens de pele castanha são marginais, quer em termos raciais quer em termos culturais. Não pertencendo exatamente ao grupo racial negro, possuem algumas caraterísticas físicas do grupo mongol. Habitam os confins áridos e remotos do sul de Angola. Não estando integrados no sistema moderno, produto dos últimos cinco séculos, rejeitaram as influências bantu e europeias e avançaram por sua conta e risco para os desertos inóspitos, em vez de competirem por terras estrangeiras mais bem irrigadas.

Parafraseando Fernandes e Ntondo, a designação khoisan, atribuída a J. Shapera e adaptada em inúmeros trabalhos, resulta da combinação das palavras Khoi - Khoin que significa "acumular, colher frutos, arrancar raízes da terra, capturar pequenos animais". Trata-se, segundo Olderogge (apud FERNANDES; NTONDO, 2002), do género de vida e modo de produção a partir do qual proveio a designação ou qualificação de um grupo humano.

\section{Operacionalização das línguas africanas em Angola}

A política linguística colonial baseava-se numa ação em favor do prestígio, da difusão e da proteção da LP em detrimento das línguas locais. Conquistada a independência, a LP continuou a gozar dum estatuto especial (por razões já apontadas); contudo, contrariamente à política colonial, a política adotada na Angola independente já visa à valorização 
das línguas africanas faladas em Angola (MINGAS, 2000), tal como é observável na Constituição da República de Angola (2010), nos pontos 1 e 2 do $\operatorname{Art}^{\circ}$ 19, nos quais se estabeleça que "a LO da República de Angola é o Português, e que o Estado valoriza e promove o estudo, o ensino e a utilização das demais línguas de Angola [isto é, das Línguas Africanas faladas no território nacional], bem como das principais línguas de comunicação internacional".

No Art 21 da mesma Constituição lê-se que o Estado deve "proteger, valorizar e dignificar as línguas angolanas de origem africana, como património cultural, e promover o seu desenvolvimento, como línguas de identidade nacional e de comunicação”.

Para isso, concedeu-se ao ILN, entre outras, as funções de "realizar estudos científicos sobre as línguas nacionais; contribuir para a normalização e ampla utilização das mesmas em todos os setores da vida nacional”. (SILVA, 2015, p. 37)

Semelhantemente, na Lei 13/1, de 31 de dezembro de 2001 (Lei de Bases do Sistema de Educação), no $\operatorname{Art}^{\circ} 9^{\circ}$, encontra-se o primeiro passo em direção à proteção e valorização das línguas nacionais depois da independência, o que constitui uma valorosa conquista no seio da cultura angolana. De acordo com Silva (2015, p 50),

em agosto de 2004, após a realização do $2^{\circ}$ Encontro Nacional sobre Línguas Nacionais, o Ministério da Educação admitiu a hipótese de introduzir, no sistema de ensino, algumas línguas locais consideradas nacionais. Atualmente, urge definir uma política linguística de caráter psicossocial, cultural e política (sic), obviamente reforçada por interesses económicos que, hoje, se inserem num contexto mundial, de forma a atribuir um estatuto às línguas angolanas de origem africana.

A maior dificuldade prende-se, entretanto, com a implementação destas decisões legais (SILVA, 2015), porque apesar de os projetos existirem desde a independência, as línguas nacionais continuam a não merecer a devida valorização (o que é patente na ausência e na não inserção das mesmas na esfera sociopolítica-administrativa do país), "não gozam de nenhum estatuto definido, servindo somente de línguas de comunicação a micronível, isto é, elas são operacionais só entre os membros de um mesmo grupo etnolinguístico 
ou de uma mesma comunidade linguística" (FERNANDES; NTONDO, 2002, p. 18). São igualmente utilizadas em alguns domínios religiosos bem como em alguns órgãos da comunicação social (pública), como a RNA e a TPA.

No que diz respeito à inclusão das línguas nacionais no sistema de ensino, Chicuna (2015, p. 43) defende que as mesmas "devam ser ensinadas a cada respetivo grupo etnolinguístico, e que todas elas merecem, por parte do Estado, uma atenção igualitária".

Que todas as línguas nacionais, sem exceção, devem merecer por parte do Estado a mesma atenção no que compreende a "criação de condições para a sua investigação, ensino e promoção" (CHICUNA, ibidem) não é objetável. Todavia, a estratégia do seu ensino a nível regional pode apresentar um senão, uma vez que não resolveria as limitações apresentadas por Fernandes e Ntondo, quando sustentam que "as línguas nacionais servem somente de línguas de comunicação entre os membros de um mesmo grupo etnolinguístico ou de uma mesma comunidade linguística", acentuando ainda mais os regionalismos. Limitar o ensino das línguas nacionais aos respetivos grupos etnolinguísticos não alargaria o seu espaço de difusão para uma abrangência nacional. Achamos, contudo, que uma possível estratégia para dirimir, ou, no mínimo, atenuar esses regionalismos, seria a implementação das línguas nacionais de origem africana em todos os níveis de ensino. Logo, ao longo dos anos de escolaridade, a começar desde os primeiros, para que se possa, desde cedo, incentivar a aprendizagem e o gosto pelas línguas nativas, elas deveriam ser ensinadas como disciplinas obrigatórias dos curricula escolares, em todos os níveis de ensino.

\section{O kimbundu - sua importância no contexto geolinguístico angolano}

O kimbundu, cujo significado quer dizer linguagem de pretos, segundo Chatelain (1889-89, p. 11), é uma das línguas bantu do rico contexto linguístico angolano. Assim 
como o termo $k i$-mbundu, as expressões $a$-mbundu ${ }^{15}$ e $m u$-mbunbu ${ }^{16}$, refere CHATELAIN, "constam de uma base comum mbundu e dos prefixos mu-, a- e ki-, significando mu(pessoa), $a-$ (pessoas) e ki- (linguagem)".

O Kimbundu é a língua falada pelo $2^{\circ}$ maior grupo etnolinguístico de Angola, os Ambundu, totalizando um número de falantes não superior a 1.500. 000, cuja área de difusão já anteriormente mencionamos. De acordo com a classificação de Guthrie, isto é, a classificação das línguas bantu por Zonas, o Kimbundu, a par do Kikongo, pertence à Zona H (FERNANDES; NTONDO, 2002, p. 43, 93). "Dados do Censo de 2014 revelam que o Kimbundu é a terceira $\left(3^{\mathrm{a}}\right)$ língua com maior número de falantes em Angola, com uma percentagem à volta de 7,82\% de locutores" (HAGEMEIJER, 2016).

A língua Kimbundu foi sempre uma das línguas nativas de Angola com maior expressão, tendo sido “a primeira língua angolana a ser estudada e escrita pelos missionários [...], nos séculos XV e XVI" (ZAU, 2011, p. 96), razão pela qual Chatelain a considerou 'língua geral do antigo reino de Angola' (op. cit. p. 9). Atualmente, é ainda visível a sua influência na esfera contextual da cultura angolana, sendo, em conformidade com Zau (2011, p. 64), "aquela que, entre as várias línguas africanas de Angola, mais influência tem exercido quer no PE, quer na própria VAP, nos vários níveis de descrição linguística, fundamentalmente no enriquecimento lexical".

\section{Interferências lexicais do kimbundu na VAP}

Como se sabe, o contato entre línguas resulta em interferências, fenómeno linguístico que consiste na utilização de estruturas e de elementos linguísticos de uma língua ('língua de partida') na outra ('língua de chegada'), "permitindo o surgimento de novas unidades lexicais em cada sistema linguístico em presença” (CHICUNA, 2015, p. 112).

\footnotetext{
15 Pretos ou pretas (ibidem).

16 Um preto ou uma preta (ibidem).
} 
Assim, o contato entre a LP e as LAs faladas em Angola tem gerado "particularidades assinaláveis que distinguem a VAP da norma europeia, fruto das interferências, diretas ou indiretas, da gramática das LB (RAPOSO, op. cit., p. 161), (UNDOLO, op. cit., p. 286)," "resultando na criação de novas palavras e expressões forjadas pelo génio inventivo popular, bem como certos desvios à norma padrão do PE, imprimindo-lhe uma nova força, vinculando-a, adaptando-a, cada vez mais, à realidade sociocultural angolana" (SILVA, 2015, p. 36). Neste aspeto, "O Kimbundu assume um papel preponderante no universo das línguas nacionais de origem africana, por ser, de longe, a língua de onde emana a maior quantidade de neologismos (angolanismos) presentes quer no português PE quer no PB (ZAU, 2011, p. 73)".

A interferência linguística pode observar-se em todos os níveis da língua: tanto a nível da estrutura do léxico como ao nível gramatical. No concernente a isto, Mingas complementa que "o nível lexical é, sem sombra de dúvidas, o mais rico em fenómenos de interferência, se se tiver em linha de conta que ele constitui a parte menos rígida de uma língua" (op. cit., p. 59).

Tendo em conta aquilo que interessa para o presente trabalho, não constitui nosso objetivo fazer uma descrição exaustiva sobre as interferências do Kimbundu na VAP. Embora as mesmas se observem noutras esferas da língua, isto é, a nível lexical, fónico e morfossintático, será aqui destacado apenas o aspeto lexical, por, como o demostraremos, ser a base do uso do morfema só como fórmula de cortesia.

Porque as realidades linguísticas nunca são completamente homogêneas, em decorrência de fatores que vão desde os geográficos aos de estratificação social e os diferentes graus de formalismo das ocasiões de comunicação (MARQUILHAS, 1996, p. 563), o contato entre a LP e as LAs resultou numa mudança linguística, "fenómeno que afeta as línguas no seu porvir histórico" (MINGAS, 1996, p. 510), dando origem à VAP, que, naturalmente, em muitos aspetos se distingue da Variedade Europeia. Uma das estruturas ou sistemas onde se nota maior transformação e que, por isso, distingue notavelmente ambas as varie- 
dades é o campo lexical, no qual algumas palavras restringem o seu significado, outras estendem-no, como é o caso do morfema só, cuja extensão semântica é o mote deste trabalho; outras ainda sofrem uma profunda alteração semântica, com o passar do tempo (MATEUS; CARDEIRA, 2007, p. 45).

Assim, além do uso já bastante generalizado de palavras como kuiár ${ }^{17} k_{\text {izomba }}{ }^{18}$ buê19, kota $^{20}$, apenas para referir algumas, tem-se registado, na VAP, a emergência de outras tantas palavras importadas do Kimbundu, não só pertencentes a grupos abertos (como as que apontamos), mas também expressões que fazem parte de grupos fechados, como é o caso do morfema só, usado na VAP com a função pragmático-semântica de favor. Cremos que a razão deste fenómeno ou desta mudança ${ }^{21}$ decorre do contanto, bastante remoto, entre a PL e as LAs, posto que nestas situações (em que o grau e a extensão do contato resulta duma convivência bastante alargada)

podem ocorrer, grosso modo, dois quadros: i) criação de bilinguismo dos falantes (o que implica a manutenção da Língua de Origem (LO, a partir daqui) e influências desta sobre a Língua Alvo (LA, a partir daqui) e vice-versa) ou ii) abandono progressivo (...) da LO, por adoção da LA como única língua da comunidade. (MINGAS, 1996 p. 513)

${ }^{17}$ É muito provável que a expressão kuiár, bastante popular na VAP, seja um empréstimo proveniente do Kimbundu, uma vez que nesta língua o verbo é empregado para se referir a algo agradável, ou que saiba bem. A analogia com o Kimbundu tem como fundamento primeiro a ocorrência nessa língua bantu do verbo kuiáia, do qual, por apócope do ditongo crescente -ia e por paragoge da desinência do infinitivo - $r$ proveio, cremos, o verbo kuiár. Por outro lado, tomando em conta a carga semântica do verbo kuiáia em Kimbundu, que remete para algo agradável, pois 'diz-se do azeite a ferver ou do toucinho a derreter-se, acto de fervilhar ou de rechinar', acreditamos ser esta a origem do verbo kuiár na VAP (cf. ASSIS JÚNIOR, op. cit., p. 182).

18 Termo Kimbundu, que significa, dança, folguedo, diversão.

19 Contração da preposição bua (ou bu) e do pronome pessoal eie (usado na VAP como advérbio de intensidade/quantidade), (Cf. ASSIS JÚNIOR, op. cit. p. 25).

${ }^{20}$ Abreviação de mákota ou dikota (os mais velhos, os maiores; os superiores...). Contudo, mais do que simplesmente fazer referência à superioridade etária, o semantismo dos adjetivos/nomes kota, mákota, dikota remete para a idoneidade. Portanto, um kota é-o, no verdadeiro sentido da palavra, não só por ser o maior em idade, mas, e acima de tudo, pela sua responsabilidade e idoneidade, bem como pelo seu saber e riqueza.

${ }^{21}$ Referimo-nos às mudanças decorrentes de influências exógenas ou externas (a que está exposta a maioria das línguas), resultantes do contato de uma língua com outras realidades culturais, sociais e políticas, apesar de as alterações dessas causas externas incidirem também na estrutura interna da língua ou das línguas em contato (MATEUS; CARDEIRA, 2007, p. 43-44). 
A política linguística colonial, em Angola (e não só), como vimos, tendeu para o segundo quadro. Porém, mesmo sob a intensa pressão da LP (LA) sobre as LAs (LO), não se deu a glotofagia das línguas nativas, o que permitiu o surgimento do primeiro quadro; ou seja, não tendo havido a morte das LO, criou-se, em Angola, um estado de bilinguismo. Ora, "quando este processo implica a passagem de gerações, o sistema de cada uma das línguas sofre grandes alterações, não só porque a mudança interna ${ }^{22}$ terá, entretanto, operado, como porque o contato terá tido como consequência a importação extensiva de traços da outra língua" (MOTA, 1986, p. 520). Nos casos como o de Angola (em que há condições de forte convivência, por um lado, e o reconhecimento da LA como elemento sine qua non para a inserção e ascensão social, por outro),

os falantes da LO tendem a aproximar-se progressivamente do sistema da LA, introduzindo-lhe modificações em parte explicáveis pelo sistema prévio que possuem da sua língua (...), podendo acontecer que a LA venha a ser afetada pela versão que dela própria falam os nativos da LO, ou pela própria LO. (MINGAS, 1996, p. 511)

\section{Considerações finais}

A ausência de uma política linguística efetiva para as línguas locais contribui, explicitamente, para a singular hegemonia da LP, por um lado, e para o desconhecimento e desinteresse pelas mesmas, por outro, de tal maneira que "a maioria dos descendeste de famílias urbanas não fala nenhuma das línguas nacionais, porque, até hoje, lamentavelmente, ainda paira na consciência de mutos angolanos que falar uma 'língua pátria' (usando a linguagem de Chatelain) é sinónimo de atraso social e de incultura. Claro que isto é um resquício da política colonial em relação às línguas africanas. Mas convém ter patente que

\footnotetext{
22 "Mudança inerenta a qualquer língua e que tem a ver com o funcionamente do próprio sistema. Trata-se de um processo do mesmo tipo ao que ocorre em relação à mudança decorrente de situações de contato linguísico mas com origens diferentes e consequencias diversas" (MATEUS; CARDEIRA, 2007), (MOTA, 1996).
} 
a cultura de qualquer sociedade humana estabelece uma interdependência com a língua, "porque esta é reflexo daquela" (IORDAN, 1937, apud ELIA, 1978, p. 216), embora a língua não seja, claro, o único traço identitário-cultural de um povo. Pelo fato de a mesma estabelecer traços muito estreitos com a cultura, pode-se mesmo afirmar que na língua está a cultura, o que significa que desvalorizar uma língua é desvalorizar a cultura da qual a língua faz parte (LIMA, 1987).

Sendo a língua suporte de identidade cultural, e uma vez que ela constitui um património da comunidade que a usa, urge a necessidade de se conservar e de se valorizar as línguas bantu faladas em Angola, tornando-as dinâmicas e "promovendo-as em todas as formas de expressão cultural", como defende a Declaração Universal dos Direitos Linguísticos (1996), publicada em Barcelona, no Artigo 41 ${ }^{\circ 23}$, sob pena de existirem cada vez menos falantes e de, consequentemente, se perder o acervo linguístico-cultural nacional; pois que, afinal, "a cultura não é geneticamente transmitida, mas herdada socialmente” (LIMA, 1987, p. 67).

\section{LA VARIEDAD ANGOLEÑA DEL PORTUGUÉS: CONTEXTO HISTÓRICO Y (SOCIO)LINGÜÍSTICO}

RESUMEN: La convivencia de la lengua portuguesa con las lenguas de Angola ha propiciado la formación de una variedad del portugués que, en diferentes momentos de la historia de ese país africano, se ha diferenciado y sigue diferenciándose de la variedad europea, originando la variedad angoleña, cuya consolidación empezó, sobre todo, a partir de la independencia, en 1975, con la oficialización de la lengua europea. Así, el presente texto pretende trazar un panorama sociolingüístico e histórico que tendrá como base el abordaje de la situación de la lengua portuguesa en Angola, en dos fases distintas de su historia. No dejaremos de observar, igualmente, la importancia del quimbundo en el enriquecimiento del acervo lingüístico de la variedad angoleña del portugués (VAP).

Palabras clave: Variedad angoleña del portugués; Sociolingüística; Lengua nacional; Interferencias; contacto; Razones históricas.

\footnotetext{
${ }^{23}$ Disponível em www.dhnet.org.br/direitos/deconu/a_pdf/dec_universal_direitos_linguisticos.pdf, consultado a 16 de março de 2018.
} 


\section{REFERÊNCIAS}

CHATELAIN, H. Gramática elementar do kimbundu ou lingua de Angola. Genebra: Typ. De Charles Schuchardt, 1888-89.

CHICUNA, A. M. Portuguesismos nas línguas bantu: para um dicionário português-kiyombe. 2. ed., Lisboa: Edições Colibri, 2015.

COSTA, T. M. Umbundismos no português de Angola: uma proposta de um dicionário de umbundismos. Lisboa: Faculdade de Ciências Sociais e Humanas da Universidade Nova de Lisboa, 2015.

DESHAIES, B. Metodologia de Investigação em Ciências Humanas. Lisboa: Instituto Piaget (1992).

DUCROT, O., TODOROV, T. Dicionário das ciências da linguagem. 6. ed.. Lisboa: Publicações Dom Quixote. (Obra original publicada em 1972), 1982.

ELIA, S. Orientações da lingüistica moderna. 2. ed., revista e ampliada. Rio de Janeiro: Ao Livro Técnico, 1978.

FERNANDES, J.; NTONDO, Z. Angola: povos e línguas. Luanda: Editorial Nzila., 2002.

GONÇALVES, R.. "Mudança linguística e variação no português de São Tomé e Príncipe”. In: ROQUE, A. C., SEIBERT, G.; MARQUES, V. (eds./coord.). Livro de atas: colóquio internacional São Tomé e Príncipe numa perspectiva interdisciplinar, diacrónica e sincrónica (edição digital). Lisboa: Instituto Universitário de Lisboa (ISTE-IUL), Centro de Estudos Africanos (CEA-IUL), Instituto de Investigação Científica Tropical (IICT), 2012. Consultado a 13 de março, 2018, de https://books.google.pt/books?isbn=989732089X.

HAGEMEIJER, T. "O português em contato em África”. In: MARTINS, A. M.; CARRILHO, E. (Eds.). Manual de linguística portuguesa (vol. 16). Berlim; Boston: De Gruyter., 2016. p. 43-67.

HAUGEN, E. "Línguas nacionais e internacionais". In: HILL, A. A. Aspetos da linguística moderna. 2. ed.. São Paulo: Cultrix, 1974. p. 106-116.

KUKANDA, Vatomene. Notas de Introdução à linguística bantu. Lubango: Universidade Agostinho Neto, 1986.

LIMA, A. M., MARTINEZ, B.; FILHO, J. L. Introdução à antropologia cultural. 7. ed., Lisboa: Editorial Presença, 1987.

MARQUILHAS, R. "Mudança linguística”. In: FARIA, I. H., PEDRO, E. R., DUARTE, I.; GOUVEIA, C. A. M. (org.). Introdução à linguística geral portuguesa. Lisboa, Editorial Caminho, p. 563-589, 1996.

MATEUS, M. H. M.; CARDEIRA, E. Norma e variação. Lisboa: Editorial Caminho, 2007. 
MATOS, N. de. Memórias e trabalhos da minha vida (Vol. I). Coimbra: Imprensa da Universidade de Coimbra, 2004.

MINGAS, A. A. Interferências do kimbundu no português falado em Lwanda. Luanda: Edições Chá de Caxinde, 2000.

MOTA, M. A. C. da. “Línguas em contato”. In: FARIA, I. H., PEDRO, E. R., DUARTE, I.; GOUVEIA, C. A. M. (org.). Introdução à linguística geral portuguesa. Lisboa, Editorial Caminho, 1996. p. 505-549.

OBENGA, T. Les bantu: peuple et civilisations. France: Présence Africaine, 1985.

RAPOSO, E. et alii (orgs.). Gramática do português (vols. I e II). Lisboa: Fundação Calouste Gulbenkian, 2013.

REDINHA, J. Distribuição étnica de Angola. Luanda: Instituto de Investigação Cientifica de Angola, 1975.

SILVA, A. P. M. da. Lexicografia bilingue de especialidade e dicionário português-kimbundu no domínio da saúde. Lisboa: Faculdade de Ciências Sociais e Humanas da Universidade Nova de Lisboa, 2015.

UNDOLO, M. E. Caraterização da norma do português em Angola. Évora: Universidade de Évora, 2014.

WHEELER, D.; PÉLLISSIER, R. História de Angola. 6. ed., Lisboa: Edições Tinta-da-china, 2016. (Obra original publicada em 2009).

ZAU, D. G. (2011). A língua portuguesa em Angola: um contributo para o estudo da sua nacionalização. Covilhã: Universidade da Beira Interior, 2011.

Recebido em: Aprovado em: 